\title{
O ensino da Língua Estrangeira através da literatura
}

\author{
Ivana Kátia de Souza Ferreira* \\ Laura Nelly Mansur Serres ${ }^{* *}$
}

Resumo: A partir dos documentos que orientam o ensino de línguas estrangeiras (LE) na escola, somados aos aportes teóricos oriundos das áreas de cognição humana e da literatura, este artigo tenta contribuir com o estudo e a reflexão acerca de como o trabalho com a literatura pode ser um recurso pedagógico eficaz que possibilite contextos mais significativos de aprendizagem. Analisa também que, além do ensino específico da sua área de conhecimento, o professor de LE tem a responsabilidade de contribuir com a escola na formação de leitores. A criatividade e o jogo, aliados à literatura, são elementos dos quais o professor pode dispor como estratégia nas aulas de LE. A partir desses conceitos, na tentativa de corroborá-los, este artigo ainda relata uma experiência bilíngue (espanhol e inglês) de ensino-aprendizagem em LE com literatura nas aulas do Projeto Amora, no Colégio de Aplicação da Universidade Federal do Rio Grande do Sul.

Palavras-chave: Escola; Língua Estrangeira; Literatura; Criatividade; Jogo.

Abstract: Based on the documents related to the foreign language teaching at Elementary School and the theoretical approaches from the human cognition and the literature fields, this paper tries to contribute to study and reflection about how

* Professora de Inglês do CAp/UFRGS. Mestre em Letras, na área de Linguística, pela PUCRS. E-mail: ivana.ferreira@terra.com.br.

** Professora de Espanhol do CAp/UFRGS. Mestre em Letras, na área de Literatura Infanto-Juvenil, pela PUCRS. E-mail: laumansur@hotmail.com. 
the work with literature can be an efficient pedagogic resource able to offer more significant learning contexts to students. It analyses that, besides the specific teaching of his knowledge field, the foreign language teacher also has the responsibility to contribute to the formation of readers at school. Creativity and games, as well as literature, are elements that can be explored by the teacher as strategy for his foreign language classes. With those concepts, as an attempt at corroborating them, this paper also presents a Spanish-English bilingual experience of foreign language teaching-learning with literature in Projeto Amora (Amora Project), at Colégio de Aplicação (Aplicação School) of Universidade Federal do Rio Grande do Sul (Federal University of Rio Grande do Sul/Brazil).

Keywords: Elementary School; Foreign Language; Literature; Creativity; Game.

\section{Introdução}

Nas diversas áreas do Ensino Fundamental, a escola brasileira vem demonstrando interesse na aplicação de novos recursos pedagógicos, capazes de possibilitar contextos mais significativos de aprendizagem, buscando uma maior participação e um maior interesse por parte dos alunos nas atividades escolares (BRASIL, 2001).

Com o intuito de qualificar a educação, os documentos que orientam o ensino de Língua Estrangeira, doravante LE, no Ensino Fundamental alertam sobre a necessidade de selecionar textos adequados para trabalhar com os alunos a oralidade e a produção textual. Sobre isso, os Parâmetros Curriculares Nacionais para o Ensino Fundamental salientam que, na hora de escolher materiais para desenvolver a produção textual e oral dos alunos, o professor de LE deve priorizar os textos com os quais os estudantes tenham familiaridade como usuários de sua língua materna. O referido documento afirma que "[ $[.$.$] uma maneira de$ facilitar a aprendizagem do conhecimento sistêmico e colaborar 
para o engajamento discursivo da parte do aluno é [...] fazê-lo se apoiar em textos orais e escritos que tratam de conhecimento de mundo com o qual já esteja familiarizado" (BRASIL, 2001, p. 33) e complementa:

Assim, para ensinar um aluno a se envolver no discurso em uma língua estrangeira, aquilo do que trata a interação deve ser algo com o qual já esteja familiarizado. Isso pode ajudar a compensar a ausência de conhecimento sistêmico da parte do aluno, além de fazê-lo sentir-se mais seguro para começar a arriscar-se na língua estrangeira. O conhecimento de mundo referido nos textos pode ser ampliado com o passar do tempo e incluir questões novas para o aluno de modo a alargar seus horizontes conceptuais, o que, aliás é uma das grandes contribuições da aprendizagem da Língua Estrangeira (BRASIL, 2001, p. 33).

O professor de LE, engajado na proposta transformadora da educação atual, que reconhece o compromisso com a formação do leitor, poderá buscar, nos diversos materiais literários, recursos favoráveis ao processo de ensino-aprendizagem de sua área de conhecimento. Tal ação corrobora a ideia de que o livro didático não deve constituir-se em material exclusivo nas aulas de línguas. Ao contrário, cabe também ao professor de LE delinear estratégias que levem a resgatar o papel da literatura na escola, valorando a experiência de vida do aluno reconhecida nas obras literárias.

Este artigo pretende, então, motivado pelas orientações/ concepções do processo ensino-aprendizagem atual, valorizar a literatura na aula de LE como mais um meio disponível no espaço educativo. Com esse intuito, fazemos uma aproximação entre diversos teóricos, tanto da área da cognição humana quanto da área da literatura, bem como apresentamos uma experiência bilíngue (espanhol e inglês) realizada na turma Amora I/2011, correspondente à $5^{\mathrm{a}}$ série do Ensino Fundamental, do Projeto Amora, do Colégio de Aplicação da Universidade Federal do Rio Grande do Sul (UFRGS), composta de 37 alunos. 


\section{O material literário utilizado na aula de LE}

A tarefa de seleção dos materiais por parte do professor pode e deve incluir textos literários adequados à faixa etária dos alunos, o que se constitui num recurso útil, no sentido de auxiliar na consecução de resultados positivos no processo ensinoaprendizagem de LE. Considerando que esse tipo de texto faz parte do mundo da criança, é possível pensar que é apropriado para trabalhar na aula de LE, principalmente quando é rico de elementos maravilhosos, como o são os contos de fada, por exemplo. Como afirma Bettelheim, "[...] os contos de fadas deixam à fantasia da criança o modo de aplicar a ela mesma o que a estória revela sobre a vida e a natureza humana" (1978, p. 59).

Além disso, esses textos merecem ser trabalhados na escola porque colaboram com o equilíbrio emocional das crianças. Para Bettelheim, a simbologia dos contos maravilhosos fornece respostas a questões mobilizadoras e " [...] oferece figuras através das quais as crianças podem externalizar o que se passa na sua mente de modo controlável" (1978, p. 82). Assim, "quando todos os pensamentos mágicos da criança estão personificados num bom conto de fadas - seus desejos destrutivos, numa bruxa malvada; seus medos, num lobo feroz; $[. .$.$] -, então a criança$ pode finalmente começar a ordenar essas tendências contraditórias" (BETTELHEIM, 1978, p. 82). O autor salienta que esses contos "[...] mostram à criança de que modo ela pode personificar seus desejos destrutivos numa figura, [...] identificar-se com uma terceira, $[\ldots]$ e daí para diante, como requeiram suas necessidades momentâneas" (1978, p. 82).

Desse modo, Bettelheim (1978) faz ver que a adequabilidade das histórias maravilhosas decorre do caráter simbólico do gênero, vinculando esses benefícios à noção de que a história traduz os conflitos interiores da criança, assim como suas possíveis soluções. A leitura do texto pode, com efeito, levar ao reconhecimento e à superação do problema. Salienta-se que o mesmo autor reconhece a importância de, depois da leitura, 
a criança meditar sobre os contos que lê ou que lhe são lidos, com o propósito de que não seja diluída a impressão suscitada por essas histórias.

Por essas razões, é fundamental delinear estratégias na aula de LE que permitam ao aluno continuar pensando na história, refletindo sobre ela e falando sobre o assunto. Nessa perspectiva, as ideias de Gardner (1994) também corroboram a importância de que os textos disponibilizados à criança se relacionem com a sua realidade e levantem questões significativas para ela:

As compreensões infantis da mente e da matéria afetam fortemente seus roteiros sobre os objetos e eventos mais universalmente encontrados no mundo - a pedra caindo, o amigo triste.

Mas a criança também tem registrado conhecimento de muitos outros conjuntos de eventos geralmente encontrados e, talvez, mais idiossincráticos. Seus roteiros incluem não apenas a festa de aniversário, $[\ldots]$ mas também as férias da família, a ida ao estádio, a excursão à loja de brinquedos, o passeio de carro, $[\ldots]$; não apenas eventos que elas testemunharam com seus próprios olhos, mas também enredos e personagens que elas viram na televisão ou no cinema, ou sobre os quais aprenderam nos livros.

As crianças esperam ler e ouvir sobre exemplos destes roteiros - ou variações deles - no seu currículo escolar (GARDNER, 1994a, p. 88).

Desse modo, o autor conclui que,

[...] na medida em que o que lhes é ensinado [às crianças] é compatível aos conjuntos de eventos canônicos, tais matérias serão prontamente assimiladas, mas na medida em que tais sequencias de eventos recentemente encontradas conflitam com roteiros muito arraigados, as crianças podem distorcê-las ou ter dificuldade em assimilá-las (GARDNER, 1994a, p. 88).

Essa linha teórica justifica a escolha por trabalhar com histórias maravilhosas na aula de LE, já que tratam de assuntos próximos à realidade infantil e podem desencadear resultados positivos no âmbito emocional dos alunos, redundando numa boa disposição para aprender e participar.

As ideias de Bordini e de Aguiar (1993, p. 13) também sustentam o trabalho com histórias. Afirmam que 
a linguagem literária extrai dos processos histórico-político-sociais nela representados uma visão típica da existência humana. $\mathrm{O}$ que importa não é apenas o fato sobre o qual se escreve, mas as formas de o homem pensar e sentir esse fato, que o identificam com outros homens de tempos e lugares diversos.

A obra literária pode ser entendida como uma tomada de consciência do mundo concreto que se caracteriza pelo sentido humano dado a esse mundo pelo autor (BORDINI; AGUIAR, 1993, p. 14).

Assim, todos os livros favorecem a descoberta de sentidos, mas são os literários que o fazem de modo mais abrangente. Enquanto os textos informativos atêm-se aos fatos particulares, a literatura dá conta da totalidade do real, pois, representando o particular, logra atingir uma significação mais ampla. Nessa tarefa, a imaginação será o meio de lhe permitir vivenciar experiências alheias às suas, ampliando a sua visão de mundo.

\section{A mente infantil e a escola}

Segundo Gardner (1994a, p. 76), através da exploração regular e ativa do ambiente, a criança adquire compreensões intuitivas sobre o mundo, que a leva a pensar de maneira coerente sobre os objetos, os eventos e as pessoas ao seu redor. Na idade de cinco ou seis anos, a criança já desenvolveu de modo relevante sentidos vigorosos de três dimensões: a) no mundo dos objetos físicos, desenvolveram uma teoria da matéria; b) no mundo dos organismos vivos, desenvolveram uma teoria da vida; e c) no mundo dos seres humanos, desenvolveram uma teoria da mente, que incorpora uma teoria do self.

O autor afirma que existem "[...] teorias feitas em casa [...]" (GARDNER, 1994b) que denotam as compreensões emergentes do mundo da criança e são complementadas por habilidades em diferentes tipos de desempenho, de domínio de amplo conjunto de roteiros, de valores e de inteligências mais individualizadas. A criança leva consigo para a escola esse conjunto de teorias "feitas em casa", capacidades, compreensões, propensões, que influen- 
ciam a maneira como o novo estudante aprende as matérias recentemente encontradas. A criança utiliza essas teorias regular e criativamente e delineia inferências a partir delas. Tais teorias ou visões do mundo são úteis e poderosas e lhe permitem dar sentido, ao menos de modo provisório, à maior parte do que ela encontra no mundo. O problema é que tendem a ser ignoradas pela escola quando ela inicia a escolarização formal.

Gardner (1994a, p. 77) explica que as teorias intuitivas permanecem como formas de conhecimento potentes e, provavelmente, ressurgem quando o indivíduo sai do meio escolar. Ele destaca que, somente se essas teorias intuitivas forem reconhecidas e integradas, será possível para a criança e seus professores determinarem em que circunstâncias elas deveriam ainda ser usadas.

Salienta ainda que a criança, aos dois anos de idade, já adquiriu sentido funcional do mundo físico. Ela considera que os objetos existem no tempo e no espaço e continuam a existir, mesmo que sejam removidos de sua vista. Nutre expectativas claras sobre os comportamentos de objetos específicos, e é sobre as compreensões sensório-motoras que são construídas as teorias iniciais da criança sobre a matéria, a vida e a mente. Apresenta, assim, as Teorias Intuitivas da Criança ou "teorias feitas em casa" e diz que essas são as Teorias Ontológicas, as Teorias do Número, as Teorias da Mecânica, as Teorias sobre o Mundo dos Seres Vivos, as Teorias da Mente.

Com relação às Teorias Ontológicas, Gardner (1994a, p. 78) explica que, depois dos dois anos de idade, o conhecimento inicial da criança sobre o mundo físico sofre diferenciações mais finas. Primeiro, as distinções são totalmente grosseiras, e a criança distingue entre objetos tangíveis e não tangíveis. Depois, estabelece distinções delineadas dentro de categorias: a) objetos que se movem por seu próprio ímpeto (vivos), entre eles (animados) alguns sentem, e uma quantidade menor pensa; b) objetos que precisam ser movidos (geralmente não estão vivos), e c) objetos que não se movem (incapazes de sentir, e pensar e de desejar). $\mathrm{O}$ 
teórico afirma que a ontologia emergente da criança é importante porque os modos como ela pensa sobre classes de entes influi nos tipos de teorias que ela desenvolve sobre essas classes e nos tipos de inferências que está preparada para esboçar.

Com respeito às Teorias do Número, pode-se dizer que há uma forte e uma precoce tendência da criança para reconhecer o domínio numérico, além da preparação adequada para a enumeração. Assim, ela conta com essa capacidade para lidar com os "tipos de seres" de uma maneira numérica, para concebê-los como parte de conjuntos de diferentes tamanhos. Pode-se observar como a criança de quatro anos enumera todas as coisas. As compreensões numéricas parecem surgir naturalmente nos anos pré-escolares. É difícil imaginar como a criança poderia lidar com o ambiente na ausência de capacidades numéricas incipientes como, por exemplo, o controle de jogos, de livros, de alimentos.

No que se refere à Teoria da Mecânica, a criança tem certas concepções básicas sobre o comportamento da matéria e prontamente a divide entre objetos rígidos, por um lado, e ágeis, por outro. Nesse sentido, explica que ela, desde pequena, tem a certeza de que o aumento no impulso sempre levará ao aumento nos resultados observáveis e de que o aumento na resistência logrará resultados menos potentes. Isso a induz à convicção de que os objetos irão dirigir-se para onde estavam anteriormente orientados. Para a maioria dos propósitos cotidianos, essas suposições sobre os comportamentos dos objetos são suficientes e se revelam úteis. Desse modo, a criança, desde cerca de três anos de idade, distingue entre objetos: a) que parecem mover-se por vontade própria; b) que não podem mover-se por vontade própria; c) que podem mover-se apenas quando impelidos por forças externas.

Quanto às Teorias sobre o Mundo dos Seres Vivos, a criança, desde pequena, discrimina as classes de entes: a) os que se movem por si próprios (vivos); b) os que são incapazes de se mover sem impulso externo ("mortos" ou "não vivos"); c) os que têm uma existência natural no mundo (plantas, animais, 
minerais), e d) os que foram feitos pelos seres humanos (artefatos como máquinas, brinquedos ou edifícios). Para a criança pequena, o organismo prototípico é o ser humano. Quanto mais um organismo lembre um humano (particularmente na aparência física), mais é suposto que possua os atributos e comportamentos dos seres humanos. Essas distinções levam a uma biologia intuitiva ou popular, com características discrepantes da biologia apresentada na escola.

De acordo com Gardner (1994a, p. 82), seria educacionalmente eficaz confrontar os estudantes diretamente com as discrepâncias entre suas teorias intuitivas e aquelas que foram desenvolvidas pelos especialistas nas disciplinas. A menos que ocorra tal confrontação, é provável que as teorias intuitivas continuarão a existir, uma vez que as teorias especialistas não sejam mais sustentadas pelas circunstâncias da escola.

Sobre as Teorias da Mente, a criança desenvolve teorias para pensar a respeito da mente humana. Com elas, o ser humano tem a capacidade de considerar a existência daquele ente, chamado por ele de mente, em outros seres humanos. Assim, a criança de dois anos já está consciente de si mesma como um ente separado e, também, dos outros como indivíduos. Chama a atenção para o fato de que nem a criança de um ano nem a maioria dos animais mostrarão essa capacidade. Pelo terceiro ano de vida, a criança já está falando sobre vontades, sobre desejos e sobre medos, os quais são "sinais leves" de que está consciente de que tem mente e de que pode provocar alguns tipos de estados mentais nos outros. Pela idade de quatro anos, a criança mostrará estar apta a representar, para si mesma, o conteúdo de uma outra mente.

A criança de cinco ou de seis anos já sabe que é melhor em alguns esforços que outras, que tem certas vontades e medos, que é capaz de obediência e desobediência, de egoísmo e de altruísmo. A habilidade da criança de observar outra pessoa que tenha um conjunto de crenças diferentes das suas representa um avanço considerável. Referente aos estágios de desenvolvimento de uma Teoria da Mente, a criança se torna capaz, ao longo da 
primeira infância, de diversos níveis ordenados de sofisticação simbólica: a) no fim do período infantil, revela uma capacidade simbólica "mundana"; b) torna-se capaz de empregar conjuntos de símbolos dentro de um sistema único e pode compreender e produzir sentenças simples que se referem a sequências de eventos ou às ações de um agente no mundo; c) torna-se capaz de avaliar que símbolos representam um ponto de vista; d) reconhece que o ponto de vista de um indivíduo pode ser contrário ao efetivo estado de coisas; e) passa a considerar que alguém pode afirmar deliberadamente alguma coisa que é contrária à realidade, por exemplo, para enganar alguém ou para obter sua solidariedade.

Ressalta que os seres humanos jovens desenvolvem vigorosas teorias sobre si mesmos, sobre os outros, sobre a matéria, sobre o número, sobre a vida, sobre a mente e sobre outras coisas que lhes permitam lidar com o mundo do dia-a-dia. Tais teorias parecem surgir espontaneamente ao longo da primeira infância e desempenham um importante papel, às vezes facilitador, mas, às vezes, contraprodutivo, conforme os estudantes tentem dominar tipos de conhecimentos acadêmicos e disciplinares mais formais. Essas teorias envolvem correntes de inferências, desenvolvidas a partir de premissas básicas da teoria ou das teorias nas quais a criança está se baseando.

Considerando o exposto anteriormente, e conservando a linha de pensamento do mesmo teórico da cognição humana, há condições de se afirmar que as compreensões iniciais da mente e da matéria representam um aspecto crucial do aparato mental que a criança leva para a escola, expressando as formas como a criança pensa sobre temas acadêmicos, a menos que seja instruída deliberadamente a concebê-los de um modo diferente.

As potencialidades da criança parecem ser pouco consideradas pelos educadores da pré-escola e, ao serem negadas, a educação tende a homogeneizar e a massificar o processo ensino-aprendizagem. Essa maneira de proceder leva equivocadamente a supor que a criança constitui tabula rasa e que, consequentemente, cabe à instituição escolar oferecer subsídios 
para o desenvolvimento cognitivo da criança, desconsiderando o que ela traz de casa, equívocos e estereótipos, na primeira década de vida no mundo. A educação deveria, então, dar espaço às produções da mente infantil, valorando sua experiência de vida, sua criatividade, sua riqueza de recursos e seus momentos de versatilidade e de originalidade.

\section{A literatura e os múltiplos sentidos no espaço escolar}

Segundo Ketzer (2001), só é possível ensinar literatura e formar leitores no âmbito da escola se estabelecidos os métodos capazes de orientar o professor. Pode-se dizer que a obra literária se materializa no texto constituído pelo código verbal escrito. Tal condição explica, embora não justifique, a tendência de alguns professores usarem o texto para ensinarem regras gramaticais, ou ainda apenas para identificarem e confirmarem esquematicamente traços e características pertencentes a determinado período literário. Perde-se, com tal conduta, a possibilidade de apreciação do valor estético da obra, condição indispensável e essencial à formação de leitores.

Não é possível conceber a construção de um único sentido para um texto, por mais referencial e denotativo que seja. Assim, os processos de produção e de recepção de um texto não podem ser concebidos num sentido único e previsível. A referida autora se pergunta como "conformar" os sentidos de um texto ficcional apenas à leitura feita pelo professor, ou mesmo pelo que é proposto nos livros didáticos. A obra literária é uma peça artística cuja natureza aponta para a ambiguidade e para a plurissignificação, com vistas ao estranhamento do leitor. Por isso, não é adequado limitar o ensino da literatura à regularidade prevista por grande parte das escolas, que costumam exigir normalização nos procedimentos metodológicos, quando a "norma" do literário é justamente o "fora da norma", o possível e o imprevisível. 
Desse modo, ensinar literatura ou estabelecer métodos para tal implicam a reversão dos paradigmas da escola tradicional, assumindo as dificuldades, os riscos, os desconfortos e as desacomodações, próprios das mudanças. O professor não deve perder de vista que tal tarefa nunca será igual e, portanto, nunca será transferível de grupo para grupo, de ano letivo para ano letivo. Deverá, sim, considerar e aceitar que o imaginário de seus alunos não pode ser controlado, por mais eficientes que sejam as metodologias a sua disposição.

Zilberman (2000, p. 95) mostra que a escola, sendo a entidade que recebe a incumbência de ensinar a ler, tem, muitas vezes, interpretado essa tarefa como algo mecânico e estático, disponibilizando às crianças o instrumental necessário e automatizando seu uso, por meio de exercícios que ocupam os primeiros anos do Ensino Fundamental. A criança, ao aprender a ler, não se converte necessariamente num leitor, já que este se define, em princípio, pela assiduidade a uma instituição determinada: a literatura. É nesse ponto que o professor deve intervir, desenvolvendo estratégias que fomentem o gosto pela leitura no seu aluno.

A escola pode tomar dois caminhos diferentes. O primeiro seria quando oferece oportunidade para que sua tarefa se cumpra de modo integral, transformando o indivíduo habilitado à leitura em um leitor. O outro caminho seria quando nega essa oportunidade ao aluno, afastando-o de qualquer leitura, sobretudo dos livros, seja por ter sido alfabetizado de maneira insatisfatória, seja por rever na literatura experiências didáticas que deseja esquecer.

Para a referida autora, a proposta de que a leitura seja reintroduzida na sala de aula significa o resgate de sua função primordial de recriar imaginariamente a realidade, buscando, sobretudo, a recuperação do contrato do aluno com a obra de ficção. Desse intercâmbio, respeitando-se o convívio individualizado que se estabelece entre o texto e o leitor, emerge a possibilidade de um conhecimento do real, ampliando os limites. O recurso à literatura pode desencadear com eficiência um novo pacto entre a criança e o texto, assim como entre o aluno e o professor. 
A leitura é uma descoberta do mundo, realizada segundo a imaginação e a experiência individual. A possibilidade de múltiplas interpretações impede a fixação de uma verdade anterior acabada, o que ratifica a expressão do aluno e desautoriza a certeza do professor. Com isso, desaparece a hierarquia rígida sobre a qual se apoia o sistema educativo tradicional, o que repercute em uma nova aliança, mais democrática e mais flexível, para o diálogo, entre o aluno e o professor.

Bordini e Aguiar (1993, p. 14), por seu turno, pensam que a obra literária pode ser entendida como uma tomada de consciência do mundo concreto, que se caracteriza pelo sentido humano dado a esse mundo pelo autor. $\mathrm{O}$ texto produzido permite o estabelecimento de trocas comunicativas dentro dos grupos sociais, pondo em circulação esse sentido humano. Constrói-se, na obra literária, um mundo possível, no qual os objetos e processos nem sempre aparecem totalmente delineados. Esse mundo, portanto, envolve lacunas que são automaticamente preenchidas pelo leitor de acordo com sua experiência. Em consequência, a literatura se torna uma reserva de vida paralela, em que o leitor encontra o que não pode ou não sabe experimentar na realidade. A obra literária captura, assim, o seu leitor e o prende a si mesmo, por ampliar suas fronteiras sem oferecer os riscos da aventura real.

\section{A aprendizagem formal e as "inteligências múltiplas"}

Gardner (1994b, p. 7) esboça uma nova teoria das competências intelectuais humanas, a qual desafia a visão clássica da inteligência que valorizava a aplicação dos testes de inteligência. Há evidências persuasivas para a existência de diversas competências intelectuais humanas relativamente autônomas (as "inteligências humanas"). Estas são as "estruturas da mente". A exata natureza e a extensão de cada "estrutura" individual não foram até o momento satisfatoriamente determinadas, nem o 
número preciso de inteligências foi estabelecido. Mas Gardner está convencido de que há, pelo menos, algumas inteligências, sendo relativamente independentes umas das outras e podendo ser modeladas e combinadas numa multiplicidade de maneiras adaptativas por indivíduos e culturas. Na vida comum, essas inteligências trabalham em harmonia; então, sua autonomia pode ser invisível. Quando observada adequadamente, a natureza peculiar de cada inteligência emerge com suficiente clareza.

$\mathrm{Na}$ área da educação, considera que deveria ser possível identificar o perfil ou as inclinaçôes intelectuais de um indivíduo numa idade precoce e, então, utilizar esse conhecimento para aumentar as oportunidades e as opções educacionais dessa pessoa. Pensa que seria possível canalizar indivíduos com talentos incomuns para programas de aprimoramento, bem como estruturar programas especiais de melhoramento para indivíduos que apresentem um perfil atípico ou disfuncional de competências intelectuais.

Desse modo, o autor desenvolve uma estrutura baseada na teoria das inteligências múltiplas, que pode ser aplicada a qualquer situação educacional, e considera o seu esforço como uma contribuição para a emergente ciência da cognição. São essas as teorias das inteligências às quais Gardner se refere: linguística, lógico-matemática, musical, espacial, corporal-cinestésica, interpessoal e intrapessoal. A teoria das inteligências múltiplas postula que existe um conjunto de potenciais humanos compartilhado por todos os indivíduos em virtude de sua filiação à espécie humana. Devido à hereditariedade, ao treinamento precoce ou à interação constante entre esses fatores, alguns indivíduos desenvolverão determinadas inteligências muito mais do que outros. Todo indivíduo normal é capaz de desenvolver cada inteligência até certa extensão, se tiver a oportunidade de fazê-lo.

Afirma que as inteligências interagem entre si e se baseiam umas nas outras desde o início da vida. Mesmo assim crê que, no centro de cada inteligência, há uma capacidade computacional ou um mecanismo de processamento de informaçôes que são singulares àquela inteligência particular. $\mathrm{Na}$ interação humana 
normal, encontram-se complexos de inteligências funcionando juntos, interruptamente, para executarem atividades humanas intrincadas. As capacidades intelectuais são um conjunto de blocos construtores, a partir dos quais linhas produtivas de pensamento e de ação são construídas. A teoria das inteligências múltiplas busca determinar a inserção de atividades intelectuais em áreas nas quais, até agora, foram frequentemente excluídas e defende a ideia de que as diferentes capacidades envolvem formas altamente desenvolvidas de cognição.

Defende a concepção de que os indivíduos possuem alguns domínios de competência intelectual potencial que poderão ser desenvolvidos quando existirem fatores estimulantes adequados. Postula levar a sério a natureza das tendências intelectuais inatas, os processos heterogêneos do desenvolvimento na criança e os meios pelos quais esses são formados e transformados pelas práticas e valores particulares da cultura. Considera que, até mesmo quando os mecanismos cognitivos da pessoa estão em ordem, o progresso educacional não necessariamente acontecerá. A maioria das análises psicológicas contemporâneas supõe um individuo ávido para aprender; porém, de fato, fatores como uma motivação adequada, um estado afetivo condutor da aprendizagem, um conjunto de valores que favoreça um tipo específico de aprendizagem e um contexto cultural apoiador são fatores indispensáveis no processo educacional.

Gardner observa que os responsáveis pelo planejamento educacional devem decidir que estratégias podem mais bem utilizadas para ajudar o indivíduo a atingir a competência, a habilidade ou o papel desejados. Para obter um quadro razoavelmente preciso do perfil intelectual de um indivíduo, é necessário um mês aproximadamente, enquanto está envolvido em atividades regulares de sala de aula. Tal perfil indicaria que linhas já foram iniciadas em um indivíduo, quais as que revelam um potencial evidente para desenvolvimento e que linhas são ineficazes ou apresentam alguns obstáculos. Esse tipo de avaliação difere da empregada na testagem da inteligência tradicional, ocasião em 
que a criança era confrontada por um adulto que lhe dirigia uma série rápida de perguntas, esperando que ela lhe fornecesse uma única resposta. Esses testes se restringiam a valorizar as habilidades linguísticas e as capacidades lógico-matemáticas, sem permitirem a obtenção de um quadro mais verídico das capacidades intelectuais em vigor da criança no momento, como a musical, a corporal-cinestésica ou a espacial, e de seu potencial intelectual.

É oportuno refletir sobre a necessidade de mudança de paradigma nos âmbitos social, cultural, familiar e escolar, bem como revisar os conteúdos programáticos da escola que, às vezes, são conduzidos de maneira linear e sequencial, produto do modelo consagrado socialmente.

\section{A literatura como desencadeadora do jogo na sala de aula}

Os jogos ajudam a criança a reelaborar criativamente as experiências vividas. Magalhães (apud ZILBERMAN; MAGALHÃES, 1982, p. 25) afirma que uma das ações mais ligadas à caracterização da infância é jogar como um modo e uma condição de explorar o mundo sem obrigatoriedade, apenas pela necessidade de se adaptar e de equilibrar a tensão. Com frequência, o jogo é reconhecido por desempenhar uma função importante na vida infantil, embora se espere que, ao longo do processo de desenvolvimento, a criança se afaste do jogo e o substitua por atividades úteis, só retornando ao comportamento lúdico de forma ocasional, como uma pausa recreativa. Defende a ideia de que o jogo é uma atividade gratuita, mas, apesar da gratuidade, não é incontrolada. Não resulta de uma determinação coercitiva ou pragmática; porém, deixa-se orientar por regras. É uma atividade espontânea, mas não desinteressada, pois a nenhum jogador é indiferente o resultado do seu jogo. Pode ser individual ou social, pode requerer concentração ou manifestar extroversão, pode ser um simples movimento de mão ou estar disciplinado 
por um complexo sistema de regras. Apesar disso, cada jogo é um momento único, que não se repete em todos os detalhes.

A referida autora salienta que há, porém, uma característica que, apesar da ausência de uniformidade, distingue qualquer tipo de jogo, enquadrando-o num determinado comportamento. Afirma que o jogo não é simplesmente satisfação de desejos isolados. Encenando o que não pode ser realizado fora do mundo lúdico, a fantasia ganha uma instância afetiva. A criança joga sem pensar por que joga. Jogando, ela atinge uma generalização do afeto, uma vez que os desejos e os conflitos, manifestações de sentimentos e de reações, são refletidos nos jogos.

A criança explora seus sentimentos e suas emoções através do jogo, assim como faz com o mundo exterior através de percepções. As situações do mundo real nem sempre favorecem a exploração dos sentimentos e o exame das reações da mesma forma que faz a fantasia de uma situação lúdica. O perigo fingido possibilita um ensaio de comportamento e uma aferição de sentimento que a situação de risco real não oportuniza. À medida que a criança vai-se tornando marcada pela ideologia vigente, recebida através da escola e da família, instituiçôes voltadas para a conservação e a propagação dos valores do status quo, ocorre uma alteração no papel da fantasia no mundo infantil. A fantasia não desaparece, não perde a densidade emocional e afetiva. $\mathrm{O}$ que desaparece é a manifestação franca da fantasia em atos não privados.

Outrossim, ressalta que, com o desaparecimento do faz-deconta, ocorre o retraimento de um conteúdo fundamentalmente ligado ao interesse da criança. $\mathrm{O}$ afastamento do jogo passa a ser exigido no momento em que a criança ingressa na escola. $\mathrm{O}$ estudo é uma atividade consagrada pelos valores adultos. Em decorrência disso, é observada a subtração das horas de jogo em benefício das atividades escolares tradicionais, substituição que provoca uma ruptura na experiência infantil.

Ainda para Magalhães (1982, p. 28), a nova etapa em que a criança ingressa, a da escolarização, não se caracteriza pela 
preocupação com as necessidades da criança em um sentido mais amplo. Na escola, o desenvolvimento da criança é considerado apenas como crescimento intelectual, e as mudanças de estágio, traduzidas pelo processo de aprovação ou reprovação, segundo a captação intelectual dos conteúdos ministrados, são representativas disso. $\mathrm{O}$ retraimento do espaço lúdico instaura um desequilíbrio, porque o jogo é uma forma peculiar de exploração do mundo pela fantasia que, restringida, cede lugar a um tipo de informação intelectual limitada sobre o mundo. O papel que o jogo desempenha na infância equivale a pensar no lugar que ele ocupa numa sociedade que valoriza o pragmatismo e a adaptação. Para relacioná-lo com a experiência literária, é preciso transcender esse mesmo lugar. Isso leva a crer que a promoção de momentos lúdicos é bem-vinda ao espaço ensino-aprendizagem.

Perroti (1982, p. 20), por sua vez, diz que a racionalidade do sistema produtivo torna o lúdico inviável, pois o tempo do lúdico não é regulável, não é mensurável, não é objetivável. Por isso, é banido da vida cotidiana do adulto, sendo apenas permitido nas esferas discriminadas dos "improdutivos" e negado dentro do mecanismo do sistema. Em seu lugar, permite-se o lazer, o não-trabalho, o que é totalmente diferente do lúdico, que é o jogo, a brincadeira, a criação contínua e ininterrupta, intrínseca à produção.

Bordini e Aguiar (1993, p. 26) referem-se a esse respeito afirmando que as atividades lúdicas vão ao encontro dos interesses da criança e do jovem, que têm no jogo o exercício simbólico das práticas sociais e dos sentimentos humanos. Suscitadas a partir de textos, essas atividades são importantes na formação e na continuidade do gosto pela leitura. Quebrando-se o sentido de obrigatoriedade, a leitura perde o caráter de disciplina escolar, para se converter em ato espontâneo e estimulante, desencadeador de momentos aprazíveis. Apontam que os textos devem agradar ao leitor e que as atividades de exploração dos mesmos devem estar comprometidas com o fortalecimento dessa reciprocidade, e não com o seu esvaziamento. 
A partir das ideias desenvolvidas até este momento, apresentaremos, a seguir, uma experiência (em andamento) realizada em sala de aula com os alunos da turma Amora I, do Projeto Amora do Colégio de Aplicação da UFRGS.

\section{Literatura e LE em sala de aula: uma experiência bilíngue}

Baseadas nas ideias teóricas desenvolvidas anteriormente, aplicamos uma atividade com literatura dentro das nossas aulas de LE. Como o próprio Projeto Amora ${ }^{1}$ incentiva, decidimos desenvolver tal atividade nas duas línguas estrangeiras estudadas pelos alunos da turma Amora I ( $5^{\text {a }}$ série do Ensino Fundamental), quais sejam, o espanhol e o inglês, na mesma aula.

Com o objetivo de motivar os alunos a utilizarem as referidas línguas a partir da literatura, trabalhamos a poesia Mamuelita, la tortuga ${ }^{2}$, escrita e interpretada musicalmente em espanhol pela argentina María Elena Walsh, sendo que o projeto também prevê trabalhar com a mesma obra traduzida para o inglês. Dentre as inúmeras obras possíveis de serem trabalhadas com os alunos em sala de aula, escolhemos Manuelita, la tortuga. Abaixo, apresentamos a referida poesia, em espanhol (língua original) e em inglês.

Para mais informações, ver http://www.amora.cap.ufrgs.br/.

2 A obra Mamuelita la tortuga foi considerada pelas autoras deste artigo como uma narrativa maravilhosa no sentido de que,

[...] sem a presença de fadas, via de regra [os contos maravilhosos] se desenvolvem no cotidiano mágico, (animais falantes, tempo e espaço reconhecíveis ou familiares, objetos mágicos, [...], etc.) e tem como eixo gerador uma problemática social) ou ligada à vida prática, concreta). Ou melhor, trata-se sempre do desejo de autorrealização do herói (ou anti-herói) no âmbito socioeconômico, através da conquista de bens, riquezas, poder material, etc. Geralmente, a miséria ou a necessidade de sobrevivência física é ponto de partida para as aventuras da busca (NOVAES COELHO, 1987, p. 14). 


\begin{tabular}{|l|l|}
\hline Manuelita, la tortuga & Manuelita, the turtle \\
Manuelita vivia en Pehuajó & Manuelita used to live in Pehuajó \\
pero un dia se marchó. & But one day, she went away. \\
Nadie supo bien por qué & Nobody knew very well why \\
a París ella se fue & She went away to Paris \\
un poquito caminando & A little bit by walking \\
y otro poquitito a pie. & And another tiny bit on foot. \\
& \\
Manuelita, Manuelita, & Manuelita, Manuelita, \\
iManuelita dónde vas & Where are you going \\
con tu traje de malaquita & With your malachite suit \\
y tu paso tan audaz? & And your bold step? \\
& \\
Manuelita una vez se enamoró & Manuelita once fell in love \\
de un tortugo que pasó. & With a he-turtle who passed by. \\
Dijo: iQué podré yo hacer? & She said, "What can I do? \\
Vieja no me va a querer, & He won't love me being old. \\
en Europa y con paciencia & In Europe, with some patience \\
me podrán embellecer. & They will make me beautiful." \\
En la tintoreria de París & At the cleaner's in Paris \\
la pintaron con barniz. & They painted her with varnish. \\
La plancharon en francés & They ironed her in French \\
del derecho y del revés. & Right side and wrong side. \\
Le pusieron peluquita & They put a wig on her head \\
y botines en los pies. & And ankle boots on her feet. \\
Tantos años tardó en cruzar el mar & So many years she delayed crossing \\
que allí se volvió a arrugar & the sea \\
y por eso regresó & That, there again, she wrinkled \\
vieja como se marchó & So she went back, \\
a buscar a su tortugo & As old as she'd gone, \\
que la espera en Pebuajó. & To meet her he-turtle \\
& Who's waiting for ber in Pehuajó. \\
\hline
\end{tabular}


A seguir, descrevemos, passo a passo, as ações propostas aos alunos.

\section{$\underline{1^{\circ} \text { passo }}$}

Numa folha, entregamos as estrofes desordenadas da poesia, a fim de que os alunos as ordenassem de acordo com a música da Manuelita que ouviam. Para ordená-las, os alunos recortavam as estrofes e as colavam em seus cadernos na ordem correspondente. Trabalhamos a pronúncia e alguns aspectos gramaticais.

$2^{\circ}$ passo

Com a ajuda do dicionário bilíngue (espanhol-portuguêsespanhol), os alunos, individualmente, puderam dirimir suas dúvidas quanto às palavras desconhecidas. O significado de algumas palavras era, algumas vezes, deduzido do próprio contexto literário.

$\underline{3^{\circ} \text { passo }}$

No grande grupo, os alunos produziram frases referentes à história de Manuelita, narrada através da poesia. Essas frases, que permitiram a reconstrução da história, foram escritas no quadro e lidas pelos próprios alunos, aprimorando a escrita, bem como a pronúncia.

$\underline{4^{\circ} \text { passo }}$

Projetamos o filme de García Ferré ${ }^{3}$, em DVD, intitulado Manuelita ${ }^{4}$. Depois, fizemos a reconstrução oral e coletiva do filme.

3 O argentino Manuel García Ferré é considerado o mestre dos desenhos animados em seu país.

4 Manuelita é uma tartaruga que nasceu em Pehuajó, Argentina. Foi trazida por uma cegonha e recebida com muito amor pelo seu papai, pela sua mamãe e pelo seu vovô. $\mathrm{Na}$ infância, ela encanta a todos com o seu carisma e com a sua alegria. Vive muito feliz na companhia de seus amigos Bartolito e Topy. Decidida e inocente, Manuelita entra dentro de um balão, localizado em um parque de diversões, que se desprende do solo. À deriva, e depois de alguns incidentes, chega a Paris. A tartaruga entra para o mundo da alta costura, no qual é exitosa trabalhando como modelo. Ganha muito dinheiro através de seu trabalho; entretanto, é explorada pelo seu empresário. Sem dinheiro e decepcionada, ela fica vagando pela Cidade Luz. Os seus amigos, preocupados por não receberem notícias de Manuelita, viajam para a Europa a sua 
$\underline{5^{\circ} \text { passo }}$

Mostramos, com a ajuda da web, imagens do monumento a Manuelita, localizado na cidade de Pehuajó na província de Buenos Aires, Argentina. Comentamos a repercussão que teve a história da tartaruga tem não somente no país vizinho mas, também, em vários países do mundo (Figura 1).

\section{$6^{\circ}$ passo}

Os alunos reproduziram, através de desenho, a parte do filme considerada por eles a mais significativa. Feito isso, solicitamos a eles que escrevessem (ainda na língua portuguesa) uma frase sintetizando o seu desenho (Figura 2).

\section{$\underline{7^{\circ}}$ passo}

Dando continuidade à proposta, mostramos o clipe da música da Manuelita, para que os alunos a cantassem com a ajuda do karaokê. Alcançadas a motivação por parte dos alunos e a sua familiaridade com a história, começa, neste momento, o trabalho bilíngue (inglês e espanhol). Com essa ideia, propusemos um jogo, o Bingo de Manuelita, criado por nós. A turma foi dividida em grupos de quatro integrantes, sendo que um grupo foi constituído de cinco integrantes. Cada aluno do grupo recebeu um cartão diferente para o jogo, ou seja, em cada grupo havia quatro cartões diferentes, cada um deles acompanhado de três fichas contendo frases em espanhol. Os cartões se constituíam de três imagens relativas à história, sendo que cada imagem estava acompanhada de uma frase em inglês e de um espaço a ser completado com o equivalente em espanhol, presente nas fichas. Os cartões eram de quatro cores diferentes. Com isso, aproveitamos para repassar o vocabulário relativo às cores, em inglês e em espanhol, usando o quadro e o caderno. As frases em espanhol foram confeccionadas em tamanho visível e anunciadas por nós, a fim de que os alunos reconhecessem as frases, buscando-as dentre as fichas recebidas, para completar as

procura. Eles a reencontram e juntos retornam a Pehuajó, vivenciando divertidas situações. Em sua cidade natal, Manuelita se casa com Bartolito, formando uma família feliz. 
lacunas dos cartões. O primeiro aluno a completar o seu cartão deveria dizer BINGO. Todas as imagens e as frases utilizadas foram previamente exploradas nas duas línguas estrangeiras. Por essa razão, os alunos foram exitosos na compreensão do conteúdo linguístico oriundo da história (Figuras 3 e 4).

O nosso trabalho com a Manuelita não se encerra aqui. Pretendemos continuá-lo com os passos $8^{\circ}, 9^{\circ}$ e $10^{\circ}$, abaixo listados, que, até a escrita do presente artigo, ainda não foram desenvolvidos.

$\underline{8^{\circ} \text { passo }}$

Confecção de fantoches que representem as personagens da história de Manuelita.

$\underline{9^{\circ} \text { passo }}$

Numa folha, serão entregues as estrofes desordenadas da poesia Manuelita, la tortuga em inglês (Manuelita, the turtle), a fim de que os alunos as ordenem de acordo com a música (em inglês) da Manuelita que ouvirão. Eles terão de recortar as estrofes e de colocá-las em seus cadernos na ordem correspondente. Serão trabalhados a pronúncia e alguns aspectos gramaticais.

$10^{\circ}$ passo

Os alunos farão a encenação da história, com os fantoches já produzidos por eles, ao som da música cantada nas duas línguas (inglês e espanhol). Para isso, os alunos trabalharão em pequenos grupos, a fim de facilitar a concretização da tarefa. A obra produzida pelos alunos será apresentada às turmas de alunos dos anos iniciais do Colégio de Aplicação da UFRGS.

\section{Considerações finais}

Com este trabalho, cujos resultados ainda são parciais, permitimo-nos vislumbrar um vasto campo de possibilidades a serem exploradas envolvendo literatura e línguas estrangeiras no espaço escolar. Tal experiência nos propiciou, principalmente, pensar na prática as estratégias a partir das teorias, oportunizando 
aos nossos alunos continuarem pensando na história narrada e refletindo sobre ela. As estratégias aplicadas contribuíram para que nos convencêssemos de que ir além da simples leitura traz benefícios ao processo de ensino e de aprendizagem. A resposta, o entusiasmo, a produção dos alunos demonstram que a poesia trabalhada levantou questões significativas para os próprios alunos.

Esperamos que este breve estudo tenha podido incentivar outros professores a continuarem pesquisando sobre o assunto, a fim de contribuírem com outras estratégias que ajudem a resgatar o lugar da literatura na sala de aula de LE, inclusive. A partir da nossa experiência anteriormente relatada, foi possível perceber que não se trata de uma tarefa simples, tendo em vista as inúmeras prévias ações com as quais tivemos de nos envolver. Dentre essas, a escolha da obra, que foi feita levando em consideração o grupo de alunos, sua faixa etária, seus interesses, suas necessidades. $\mathrm{O}$ fato de ter sido uma atividade bilíngue demandou diálogo entre nós, as professoras envolvidas, bem como estudo, tempo para o planejamento das aulas e, principalmente, vontade de que a atividade se concretizasse.

Toda essa trajetória, tanto teórica quanto prática, nos possibilitou inferir que o professor de LE, tendo em vista contribuir para a ampliação da visão de mundo do aluno, ao escolher uma obra literária e dela fazer uso, pode ir muito além das questões linguísticas, oriundas da sua área de conhecimento. Questões como, por exemplo, valores que, vindas a tona, podem fomentar diálogos e reflexôes, relacionando essa experiência a novas aprendizagens, tanto de língua quanto de desenvolvimento pessoal e coletivo.

A avaliação considerada um processo integrado e contínuo, baseada na observação como seu principal instrumento e envolvendo diretamente o aluno, levou em conta não apenas a correção linguística mas, também, as interações sociais, de modo a propiciar um clima emocional favorável a uma aprendizagem efetiva. 
Figura l - Monumento de Manuelita em Peguajó/Argentina

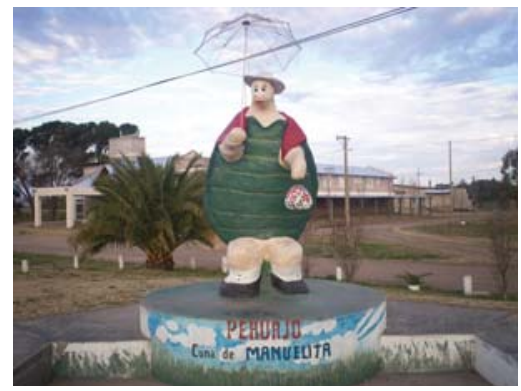

Fonte: http://kelluweng4.blogspot.com/

Figura 2 - Desenhos produzidos pelos alunos da turma Amora I/2011
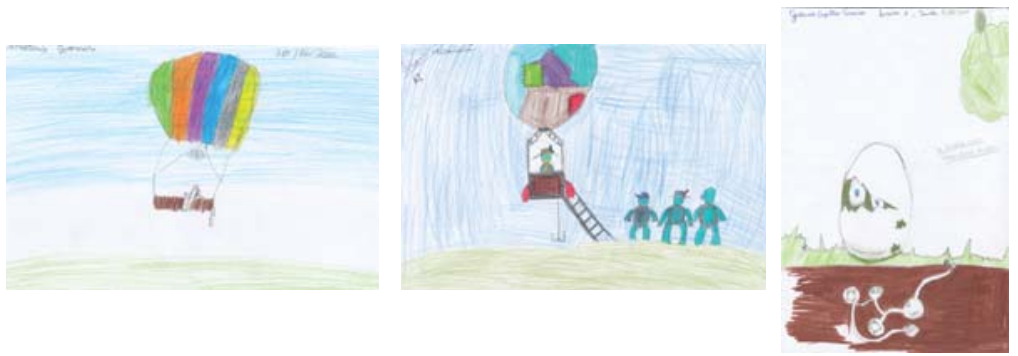
Figura 3 - Alunos da turma Amora 1/2011 em diferentes momentos da atividade com Manuelita
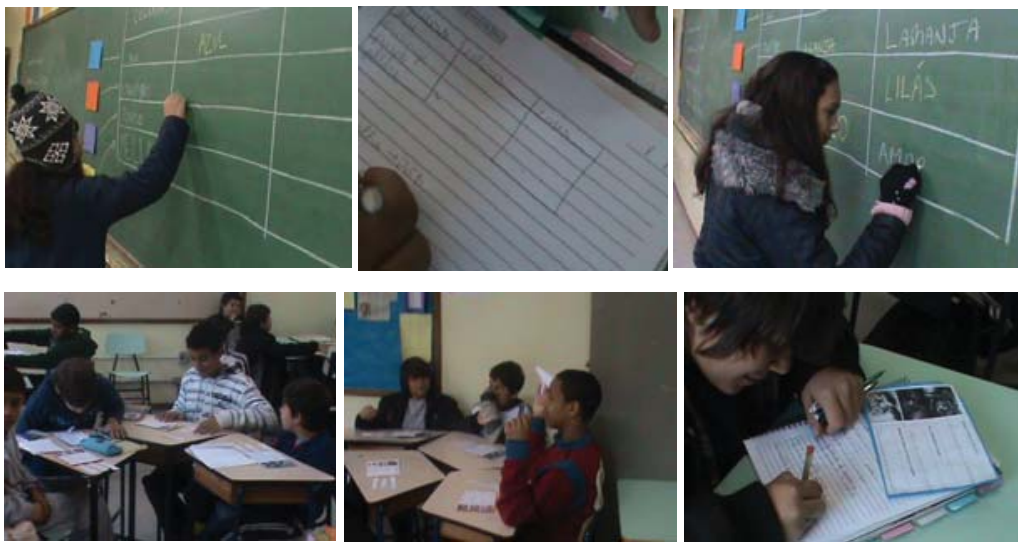

Figura 4-Minicartazes com as frases utililizadas no bingo

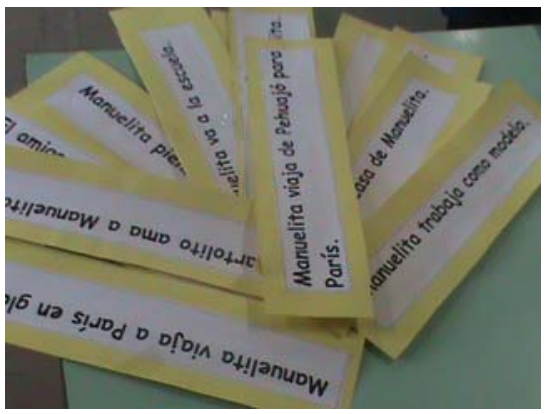

\section{Referências}

AGUIAR, Vera Texeira de. A formação do leitor. Porto Alegre: Mercado Aberto, 1993.

BETTELHEIM, Bruno. A psicanálise dos contos de fadas. Rio de Janeiro: Paz e Terra, 1978. 
BORDINI, Maria da Glória; AGUIAR, Vera Texeira de. A formação do leitor. Porto Alegre: Mercado Aberto, 1993.

BRASIL. Ministério da Educação. Parâmetros Curriculares Nacionais para o Ensino Fundamental. Brasília: SEF/MEC, 2001.

GARDNER, Howard. A criança pré-escolar: como pensa e como a escola pode ensiná-la. Porto Alegre: Artes Médicas Sul, 1994a.

GARDNER, Howard. Estruturas da mente: a teoria das inteligências múltiplas. Porto Alegre: Artes Médicas, 1994b.

KETZER, Solange Medina. A literatura e a metodologia do ensino de literatura para crianças e jovens. In: A linguagem descobrindo mundos. Erechim/RS: Universidade Regional Integrada do Alto Uruguai e das Missões - URICER, 2001.

LAJOLO, Marisa; ZILBERMAN, Regina. Literatura infantil brasileira: história e histórias. São Paulo: Atica, 1984.

MANUELITA. Direção: García Ferré. Produção: García Ferré. Buenos Aires: Leader Music, c2009. 1 DVD (90min). Baseado na canção "Manuelita, la tortuga”, de María Elena Walsh.

NOVAES COELHO, Nelly. O conto de fadas. São Paulo: Ática, 1987.

PERROTI, Edmir. A produção cultural para a criança. Porto Alegre: Mercado Aberto, 1982.

WALSH, María Elena. El reino del Revés. Bueno Aires: Alfaguara, 2000.

WALSH, María Elena. Manuelita la tortuga. Intérprete: Katie Viqueira. In: WALSH, María Elena. Los videoclips de las canciones de María Elena Walsh. Produção e animação: Diego H. Perticone. Buenos Aires: Leader Music, c2009. 1 DVD (3min48s). Faixa 2.

WALSH, María Elena. La Tortuga Manuelita. Intérprete: María Elena Walsh. In: Canciones infantiles animadas. Produção: Kids Concept, [2000?]. 1 DVD (3min48s). Faixa 1.

ZILBERMAN, Regina. Literatura infantil e aprendizagem da leitura. In: Educação em Revista. Belo Horizonte, n. 31, p. 91 a 101, junho/2002.

ZILBERMAN, Regina; MAGALHÃES, Lígia C. Literatura infantil: autoritarismo e emancipação. São Paulo: Ática, 1982. 